\title{
ONTOGENETIC CHANGES IN SOME STRUCTURES OF EARLY EMBRYOS AND LARVAE OF THE BIG HEAD CARP, ARISTICHTHYS NOBILIS
}

\author{
Nabil K. EL-Fiky \\ Department of Zoology, Faculty of Science, Tanta Univ. Egypt
}

Key words: development, gills, muscle, eye, feeding, free neuromasts, scales, big head carp, Aristichthys nobilis

\section{ABSTRACT}

$\mathrm{T}$ The present study contributes to many major topics in the developmental biology of fishes: the development of the early respiratory organs, the differentiation of red muscle layer and its specific function, the development of the visual system, the time of the first feeding, the development of mechanosensory organs (tree neuromasts) and finally the development of scales.

A provocative question on these topics could be asked: how growing structures adapt themselves to the constantly changing demands of function and behaviour?

Morphological, histological and scanning electron microscopic investigations were combined to study the ontogenetic changes in some selected structures of the developing embryos and larvae of the big head carp, Aristichthys nobilis.

It was found that the newly hatched larvae have four gill arches. After three days of hatching, small protuberances (filaments) were found on these arches during which such gills were not yet functional. Larvae of 4-5 days old possess four gill arches with series of relatively short filaments, each possesses numerous secondary lamellae (the true respiratory surface) on both sides.

The muscle regions in the pre-hatched embryo consist of scattered undifferentiated myoblasts. The body of the recently hatched larva was surrounded by a single layer of muscle fibers ( the gills were still in a rudimentary state). The larvae respire almost exclusively through the superficial layer of red muscle fibers. This layer is to great extent short after hatching but diminishes gradually by contracting towards the lateral region of the body until it merges with (or gives rise to) the proper red muscle fibers of the adult. The present study suggests that there is a close relationship between the rate of differentiation of gill structures and the rate at which the larval 
red muscle layer disappears. It seems quite clear the that red layer of muscle fibers and the secondary lamellae of gills serve as organs of gas exchange at different stages of development. This is expected if one organ is to replace the other without causing a break in respiratory function.

In newly-hatched larvae, free neuromasts were already recognized in both the head and trunk regions. During growth, the number of free neuromasts increased. In the head, free neuromasts were located around the eye and nose, their direction of maximum sensitivity. Distinct changes in free-neuromasts occurred during the formation of the canal organ. The free neuromasts were become functional as a mechanoreceptors when they well developed cupulae and can detect the origin of mechanical stimuli at this very early stage.

The visual system is poorly developed and free of pigment at hatching, and eyes were probably non-functional at this time. The development of eye pigmentation should provide a first feeding larvae with sight .

As the larvae develop, the number of the surface neuromasts gradually decreased and finally disappeared. At the same time, the canal organ was formed and the scales has advanced. The lateral-line scales extend posteriorly nearly the tail and anteriorly nearly to the pectoral girdle. Our data show clearly that the disappearance of the free neuromasts was correlated with the appearance of both retinal pigments and body scales.

It seems quite clear that right the sequence of the development of the structures necessary for vital functions appears to be' well adapted to the demands.

\section{INTRODUCTION}

- Dynamic morphology is the study of the ontogenetic transformations of functional systems in growing organisms in order to determine the nature of the qualitative and quantitative changes ((Dullemeijer, 1974; Houde, 1987 and Timmermans, 1987). Its purpose is to provide functional and ecological explainations of these transformations and to search for general rules. Important question in this type of functional developmental morphology is how growing structures adapt themselves to the constantly changing demands of function and environment. Many ontogenetic changes occur during larval life some of which relate directly to the development of the 
adult while the others are presumed to be of functional significance (Kendall et al., 1984).

Extensive developmental processes taking place in the larvae of fishes after hatching involve swimming muscles, gills, sense organs (vision and free neuromasts) and scales. Since these processes affect major biological functions, from food acquisition to mode of swimming, they should not be ignored in studying on the biology and ecology (O'Connell, 1981 and Mark, et al., 1989).

The early development of the swimming muscles and gills reflects the peculiarities of life style and habitat. After hatching, the gills of larval fish are rudimentary structures and gas exchange takes place across the whole body surface (El-Fiky et al., 1987; El-Fiky and Wieser, 1988; El-Fiky, 1989 ; Hinterleitner et al., 1989 and EL-Fiky et al. 2000). They have shown that during the first two weeks after hatching the body of cyprinid larva is surrounded by a unicellular layer of muscle fibers called red layer (representing surface of the body). The area of this layer diminshes gradually by contraction towards the lateral regions of the body. At the same time the gill filaments and secondary lamellae (representing the respiratory surface of the gills) are gradually increased in number. So, gills and red layer are related to each other by an approximately hyperbolic function, suggesting a constant product between the two organs. This is to be expected., one organ is to replace the other without causing a break in the rate of oxygen consumption.

A close correlation seems to be exist between the ontogeny of the sense organs and the change in behaviour. The newly hatched larvae possess free neuromasts. These neuromasts become functional as ' mechanoreceptors within 3-4 hours by the formation of cupulae. At this early stage, the neuromast organs facilitate the larva to detect the origin of mechanical stimuli. During this time, the eyes are free of pigments and are certainly non-functional. Within 2-4 days, the eyes become functional, cones and rods of retina increase the visual sensitivity and the larvae start swimming and feeding and the lateral line canal system was developed (Blaxter,1987; and El-Fiky, 1993a and 1994).

Little attension has been given to the early development of scales. Fisher and Pearcy, 1990 (in Coho salmon), Shackell and Doyle, 1991 (in Oreochromis niloticus) and El-Fiky, 1993b (in Cyprinus carpio) noticed an accumulation of dermal cells "The 
scleroblasts" under the epidermis which are considered to be the progenitor cells of the scale anlage.

Towards a better understanding of the role that developmental processes might possible play in the life of fish larvae, the aim of the present investigation is to illustrate the development of red layer muscles, gills, eye, presence of mechanosensory free neuromasts and developmental time of scales.

\section{MATERIALS AND METHODS}

Eggs and newly hatched larvae of the big head carp, Aristichthys nobilis, were obtained from artificial fertilization station of Fowa, Kafr EL-Sheich, Egypt. They were maintained in tanks of dechlorinated water at $20^{\circ} \mathrm{C}$.

\section{Whole mount preparations}

Whole mount preparations of specimens were accomplished by methods of Dingerkus and Uhler (1977) and Park and Kim (1984). Different stages of larvae were fixed in $10 \%$ buffered formalin for 24 hours. The fixed larvae were transferred to $70 \%$ alcohol, stained with alcian blue and alizarine red and then left in glycerol for 3 days.

For obtaining gill arches only, the operculum on either side of the head was removed. It is essential to cut the arches as close to their points of attachment as possible. The same method of whole mount preparations was used.

Scales obtained from the caudal peduncle of larvae fixed in $95 \%$ ethanol were stained in alcian blue and alizarine red, dehydrated and mounted in glycerol according to the method of Franklin and Smith (1960) and EL-Fiky (1993b). Stained scales were studied with the binocular microscope in order to observe the surface design of their circuli.

\section{Histological preparations}

Embryonic stages were carefully removed after tearing the egg shells. Embryos and hatched larvae fixed in cooled Carnoy's solution were washed briefly in absolut ethanol to remove the chloroform and stored in $70 \%$ ethanol. After not more than 4 days, the fixed specimens were dehydrated in graded ethanol series and subsequently cleared in terpeniol and embedded in paraffin. For sectioning (at $5 \mu \mathrm{m}$ ), muscles were oriented so that fibers were cut at right angles to their main axis. The part of the musculature used in this study lies directly behind the posterior dorsal fin. 


\section{SEM preparations}

For scanning electron microscopic (SEM) studies, the larvae were fixed overnight in $2.5 \%$ glutaraldehyde solutions in phosphate cacodylate buffer at $\mathrm{pH} 7.4$, dehydrated in a graded series of ethanol, dried in a critical point dryer, mounted on stubs, and sputter coated with gold palladium in a polaron E5100 unit. Specimens were viewed with JEDL JSM. 5200 according to Kawase (1996) method.

\section{RESULTS}

\section{Differentition of gill filaments and lamellae}

In Iaboratory cultures of the big head carp, the newly hatched larvae have four gill arches separated by narrow gill slits. The slits are covered by a skin fold serving as opercular flap. (pl. 1,a and b). The anteriomost arch is slightly bigger than the second arch but the third and fourth arches are considerably smaller in size compared with the first one. After three days of hatching, small protuberances appeared on these arches (Pl. 1,C). These protuberances increase in size forming gill filaments. After 4 days of hatching, surface elevations on these filaments mark the places of presumptive secondary gill lamellae on both sides of the filaments of the first and second arches, (Pl.1,d). Progressively, more secondary lamellae appear. After 7 days of hatching, larvae possess four gill atches with series of relatively short filaments, each possesses numerous secondary lamellae on both sides (pl. 1, e).

\section{Differentiation of respiratory red layer}

Differentiating epiaxial and hypaxial muscles in the prehatched embryo consist of scattered undifferentiated myoblasts. These cells were recognized with light microscope by their prominent nuclei. Cross section through the body of the newly hatched larvae, showed that some of these myoblasts migrate toward the lateral surface forming superficial single layer covering the whole body from the dorso-lateral extremities (PI. 2,a). These cells seemed to be presumptive myoblasts of monolayered red fibers. As the larvae develop, the red layer of myoblasts becomes bigger and completely separated from the underlying white muscle mass (PI. 2;b). In 7-dayold larva, the lateral constriction of the red layer became more pronounced, making the appearance of other small diameter fibers splitting from the red muscle layer. The proliferating red fibers soon fill the triangular space along the lateral line of the body; thus 
generating the true red muscle mass of the adult fish (Pl. 2,c). As the larvae develop, the superficial red muscle layer (the gills are not yet functional and gas exchange may takes place through the body surface) contracts from the dorsal and ventral edges towards the Iateral reglons of the body and finally disappeared (at the same time the gill filaments and lamellae were developed and become functional ) while the area occupied by red muscle fibers was increased.

\section{Development of surface free neuromasts}

Scanning electron microscopical inverstigations on the head and trunk regions of the newly hatched larvae, showed the presence of the free neuromasts with well developed cupulae around the mouth (Pl. 3,a ) and eyes. The neuromast has two functions: mechanoreception and chemoreception. It becomes functional as a mechanoreceptor when it has well developed cupulae. The big head carp larvae become able to ovoid an obstacle at 18 hours after hatching, when they have 5 pairs of free neuromasts and nonfunctional eyes. This indicates with no doubt that the free neuromasts are functional, and the larvae can detect the origin of mechanical stimuli at this early stage. After about 26 hours of hatching, larvae possess about 13 neuromasts on each side arranged between the eyes and around the nasal cavities (Pl. 3,b) with further 4-7 neuromasts on either side of the head. Some of these neuromasts lie in a position which suggests that they will be incorporated into the later development of the head lateral line canals ( $\mathrm{Pl}$. 3,c). In 2-day-old larva, about 20 prominent neuromasts with well developed cupulae are present on either flank (Pl. 3,d). In some places the neuromasts are paired on both sides of the body and in other places they are less regular. As the larvae develop, the number of neuromasts increases to be about 30 with further three or more on either side of the caudal fin. After 6 days of hatching, the larvae are fully developed having all the adult structures. The canal organ was formed at this stage; hyomandibular, supraorbital and infraorbital canals on the head. The cupulae are arranged in a line on the trunk and protruded from the body surface (P1. 3,e). The lateral line canal on the trunk was formed, thus completing the structure.

\section{Development of eye}

In the newly hatched larvae, the eyes are not pigmented and the lens and retina are poorly differentiated (Pl. 4,a). The presumptive neural retina is composed of a hemispherical sheet of undifferentiated neuroepithelial cells. These cells have two critical roles. (i) they 
generate the retinal cells and (ii) they provide a vertical scaffolding around which neural connections are organized. After 8 hours of hatching, the cells of the lens are arranged in two layers, cuboidal cells on the outside, and spherically arranged columnar cells on the inside ( $\mathrm{Pl}$. 4,b). During this stage, pale pigmentation is seen and the retinal cells were arranged radially and not differentiated. After 20 hours of hatching, the retina is differentiated into an inner ganglionic layer and an outer nuclear layer (visual cell nuclei) (PI. 4,c). The nuclei of photoreceptor cells are in the outer nuclear layer. The inner and outer plexiform layers are formed (Pl. 4,d), but no optic nerve fibers can yet be seen. In 4-day-old larvae, the eye is well pigmented and the cones are formed and nerve fibers from the retinal ganglion cells connect with the optic tectum (P1. 4,e and f). As the larvae grow, cones and rods increase in number, and the pigment epithelial layer becomes thicker. The morphological development of the retina increases the visual sensicivity, and can be related to changes in visual behaviour and habitat.

Development of scales

Before the appearance of the scales, the skin exhibits a stratified epidermis above the stratum compactum of the dermis. The latter is made of collagen fibrils. The basal lamina lies between the dermis and epidermis. The accumulation of elongated fibroblasts below the epidermis is the first sign of scale formation (Pl. 5,a). Each fibroblast possesses a large oval nucleus containing dense chromatin particles. The number of fibroblasts increases with time after which they differentiate into specialized cells called scleroblasts. The young scale is composed of a thin osseous layer (P1. 5,b). The first circulus of the osseous layer appears on the margin of the anterior region of the scale. Shortly after a circulus is formed, it becomes mineralized by deposits in the form of needle-like crystals. The first visible design to appear is a circulus, brightly stained with alizarin. More circuli are progressively added on the outer margin of the last one (Pl. 5, c and d). The radii differentiate, but on the anterior region of the scale exclusively ( $\mathrm{Pl} .5, \mathrm{e}$ ). Above and below the lateral line, two or three rows of scales were developed in the region just behind the posterior level of the dorsal fin. As the larval grow, the scale development has advanced. The lateral-line scales extend posteriorly nearly the tail and anteriorly nearly to the pectoral girdle. 


\section{DISCUSSION}

\section{Functional relationship between gills and muscles}

The development of gills and muscles in different types of fishes has been the subject of numerous studies (gills: de Silva, 1974; Morgan, 1974; Hughes, 1984; El-Fiky et al., 1987 and EL-Fiky, 1989; and muscles: Nag and Nursall, 1972; Proctors et al. 1980; van Raamsdonk et a ., 1978 \& 1982; Talesara and Urfi, 1987).

Larval survival is dependent upon the development of organs required for feeding and respiration. Early hatched larvae of teleostean fishes always seem to possess a superficial layer of red fibers which surrounds nearly the whole body. The fibers of this layer are actually structures through which oxygen is taken up. This layer displays some of the properties of red muscles and thus will be called the red layer (Proctors et al. 1980, Batty, 1984 and El-Fiky et al., 1987 and EL-Fiky, 1989). At the same time, the gills are not yet functional (de Silva 1974, Hughes, 1984).

In laboratory cultures of the big head carp, the newly hatched larvae have four gill arches separated by narrow gill slits. After 3 to 4 days of hatching, the gill filaments and the secondary lamellae increase rapidly in number (the true respiratory area of gills) and the gills become functional. Another differential feature which emerged from our data concerns the manner in which the newly hatched larvae possess a temporary red layer which used as a respiratory organ when the gills are nonfunctional. The rate of differentiation of gill structures is correlated with the rate at which the larval red layer of muscle fibers contracts and merges with the adult musculature.

Knowledgs of ontogenetic development of fish gills may provide an understanding of functional activity patterns of young fish. After hatching, the gills of larval fish are rudimentary structures and gas exchange take place across the whole body surface (Proctor $e t$ al., 1980; O'connell, 1981 and Batty,1984). The structure of gills during embryonic. and post-hatching development has received limited attention (Hoda and Tsukahara, 1971 and Blaxter, 1988).The morphological structure developing gills, as seen by SEM, was studied by Coughlan and Gloss (1984) on Micropterus dolomieui. EIFiky et al., 1987; El-Fiky and Wieser, 1988; El-Fiky, 1989; and Hinterleitner et al., 1989). They reported that, gills and red layer are related to each other by an approximately hyperbolic function, suggesting a constant product between the two variables; i.e., one organ is to replace the other without causing a break in the rate of 
oxygen consumption. The paper of Morgan (1974) on salmo shows that the respiration in the early stages is cutaneous. This cutaneous gas exchange is the only mechanism in newly hatched fish larvae and a gradual increase in the contribution of the gills during development is generally assumed.

The skin remains the major site of gas exchange throughout embryonic and larval period (Rombough, 1988). In Rutilus rutilus the primary filaments just begin to grow three days after hatching (ELFiky $e t$ al., 1987). At the age of nine days (rearing temperature of $20^{\circ} \mathrm{C}$ ) the number of filaments on the first gill arch is about 4. During the next 30 days these larvae grow from 1.5 to about $2.5 \mathrm{mg}$ and gills develop rapidly. A single layer of muscle fibers displaying the properties of red fibers surround the body of $R$. rutilus and other species at hatching. After 30 days of hatching, this layer is reduced from 12 to $3 \%$ of the total muscle mass of the fish. This decrease shows a close correlation with the development of number and length of gill filaments and lamellae( EL-Fiky et al., 1987).

In common carp there appears to be a triphasic allometry of gill area versus body mass. From 1.6 to $3 \mathrm{mg}$ (yolk-sac larvae) and from 3 to $200 \mathrm{mg}$ larvae positive allometric growth occurs with slopes of 7.066 and 1.22 (Oikawa and Itazawa, 1985). The juveniles from $200 \mathrm{mg}$ onward and adults of more than two $\mathrm{kg}$ show a negative allometry of gill surface to body mass with a coefficient of 0.794 . At the end of the absorption of the yolk-sac at $20^{\circ} \mathrm{C}$ the 7-day-old carp larva (about $3 \mathrm{mg}$, body weight) possesses a total gill area of about 1 $\mathrm{min}^{2}$ and. a total surface area (body and fins) of $27 \mathrm{~mm}^{2}$. The gill surface appears to grow most rapidly when the body surface is reduced during the absorption of the yolk and the consecutive size reduction of the blood vessels covering it (Balon, 1985). From these data it appears that in common carp larvae of about $6 \mathrm{~mm}$ (SL) and $1.1 \mathrm{mg}$ fresh weight the surface of the body and fins is quite large compared to the area of the gills. Hence, there is no need for the gills to develop as early as the structures needed for feeding because the oxygen required for the predominantly aerobic metabolism is available from cutaneous diffusion. The red muscle layer may support this cutaneous respiration (EL-Fiky et al., 1987).

In the developing fish, the sequence of the development of the structures necessary for vital functions appears to be well adapted to the demands. The common carp larvae which possess all the morphological tools and regulatory and steering mechanisms to 
swallow a prey do not yet need well developed gills (Drost $e t$ al., 1988). Their use as respiratory organ is not yet possible. Gills appear later in development, are gradually involved in the branchial blood circulation and still later regularly irrigated by the buccal and opercular branchial pumps. At least this part of the sequence of morphological differentiation of carp larvae appears closely related to the changing demands of functions.

The paper of El-Fiky and Wieser (1988) on A. alburnus, $R$. rutilus and $L$. cephalus shows that the red layer of muscle fibers and the secondary lamellae of gills serve as organs of gas exchange at different stages of development. The number of secondary lamellae (respiratory surface of the gills) and the relative mass of the red layer (respiratory surface of the body) are related to each other suggesting a constant product between the two variables. This is to be expected if one organ is to replace the other without causing a break in the rate of oxygen consumption.

Functional relationship between the free neuromasts and the eyes

Of 'many developmental changes occurring during the early larval period, the most important for larval bony fish may be mechanosensory and vision (Blaxter, 1987, Mukai et al. and ELFiky, 1993a and 1994).

The teleostean fish larvae of numerous species respond to water currents and disturbances at the surface and it seems likely that the free neuromasts are responsible for this sensitivity. Free neuromasts are present at hatching in a wide range fish species like northern anchovy (O'Connell, 1981), Atlantic halibut (Blaxter et al., 1983a), Atlantic herring (Blaxter et al., 1983b), plaince and turbot (Neave, 1984), Flounder, Paralichthys olivaceus (Kawamura and Ishida, 1985).

The free neuromasts have cylindrical cupulae and the effective stimulus is the torque due to the difference between the frictional forces at the end of the cupula and those at its base. These forces are.propotional to the local differences in velocity of the water and the cupula. In common carp, the cupulae are therefore well within the boundary layer and occupy the region of maximum velocity gradient normal to the fish (EL-Fiky, 1993a). Assuming that the hair cells give maintained responses for maintained displacement of the hairs (Flock, 1971; Wapp, 1975), the neuromasts could signal maintained or very low frequency differences in velocity between the fish and the surrounding water. 
: Free neuromasts, which are mechanosensory organs in larval fish, are important for the perception of physical stimuli from predators (Blaxter and Fuiman, 1989) or planktonic prey (Iwai, 1965, Jones and Janssen, 1992). A free neuromast consists of sensory cells surrounded by supporting cells and a cupula protruding from the body surface (Iwai, 1965, 1967 and 1972, Blaxter, et al. 1983b and Mukai et al. 1992). Displacement of the cupula by physical stimuli is transmitted to the sensory hairs of the sensory cells, exciting them (Dijkgraaf, 1962; Blaxter,1987; and El-Fiky, 1993a and 1994). The apical surface (sensory epithelium) of free neuromasts is the part that connects the cupula and sensory hairs, so this surface seems to be important for an understanding of free-neuromast functions. Many studies have been done of the distribution, development, and sensory-cell polarity of neuromasts (Kawamura and Ishida, 1985; Kawamura and Washiyama, 1989, Harvey, et al. 1992 and Mukai and Kobayashi, 1992 \& 1994). The development of free-neuromast functions must be related to the changes in demands during larval growth. El-Fiky (1993) revealed that a close correlation exists between the ontogeny of the sense organs and changes in behaviour.

It is known from earlier work that the visual system of the teleostean larvae is poorly developed and free of pigment at hatching (Kawamura and Ishida, 1985 and EL-Fiky 1993a). Ali (1959) reported that the eyes of the embryo of Oncorhynchus spp. contained only cones and no rods in the retina. Pure cone retinae have been demonstrated in the early stages of many teleosts from different families while the rods appear later (Blaxter and staines, 1970; Johnes, 1981; Gumas's 1982; Kawamura et al., 1984; Kawamura and Ishida, 1985; Blaxter, 1986).

A pure-cone retina is thus adequate for first feeding, and experiments showed that light is required for feeding in many species, at least in the early larval stages (Sandy and Blaxter, 1980; O'connell, 1981 and Branchek and Bremiller, 1984). Other aspects of visual performance, in relation to feeding, have been investigated, especially the perception distance for food, which increases with body length (Neave, 1984). In contrast, Kunz, et al. (1983) found a well differentiated duplex retina in the young viviparous guppy even in embryo.

\section{First feeding and the development of the eyes}

In carp larvae, sight is probably the most important sense which is necessary for feeding. Carp larvae have pure-cone retina like 
many species of fish larvae. Blaxter and Staines (1970) examined the retina of 12 species of teleostean fishes. The lack of eye pigmentation at hatching has been reported in many teleosts (Blaxter, 1986) and eyes are probably nonfunctional at this time. The development of eye pigmentation and ocular motor muscles should provide a FF (first feeding) larva with sight and the ability to move its eye. The lense retractor muscle did not develop until after FF; it was considered functional beginning at $12 \mathrm{DAH}$ (days after hatching). The lens retractor muscle develops after FF in other species of fish as well like in Northem anchovy, E. mordax, (O'Connel, 1981). This muscle allows a larva to focus on objects at different distances, theraby increasing the field of vison (Munz, 1971). In Walleye Pollock larvae, the lens retractor muscle was not functional until $12 \mathrm{DAH}$ (about a week after FF) hence, the larval field of view is restricted because it is unable to change the focus of its eyes. Thereafter, visual acuity improves, allowing such larvae to detect both prey and predators more easily (Porter and Theilacker, 1999).

Additional contributing factors may include developmental changes occurring to other organ systems including trunk musculature and lateral line system were reported in other species of fish larvae (O'Connell, 1981 and Blaxter, 1986). For Northern anchovy, E. mordax, larvae, feeding success rapidly improves during the first week of feeding (Hunter, 1972). At hatching, Walleye Pollock larvae lack functional eyes and mouth, and have a straight-tube gut. The development of these structures between hatching and FF allows larvae to begin feeding, and their continued development after FF improves the larvae's chance of survival (Porter and Theilacker (1999).

The final conclusion revealed that, a close correlation seems to exist between the ontogeny of the sense organs and the change in behaviour. The newly hatched larvae of carp attatch to the substratum. The free neuromasts were present at hatching, and become functional as mechanoreceptors when they well developed cupulae after 3-4 hours and the larvae can detect the origin of mechanical stimuli at this early stage. At this time, the eyes are free of pigment and are certainly non-functional. Within $2-4$ days, the eyes becomes functional, cones and rods of retina increase the visual sensitivity, and the larvae start swimming and feeding and also the free neuromasts increase in number. Later, the lateral line canal system was developed, and twin cones of retina increase the visual sehsitivity. 


\section{The development of the scales}

Studies on the scale morphogenesis were carried out on Brachydanto rerio (Waterman, 1970); Onchorhynchus keta (Yamada, 1971), Carassius auratus (Maekawa and Yamada, 1972); Tilapia mossambica (Lanzig and Wright, 1976); Cyprinodon variegates (Ölson and Watabe, 1980) and, Oncorhynchus kisutch and O. nerka (Jolliee, 1983),

The early development of scales has received only limited attention. Fisher and Pearcy, 1990 (in Coho salmon), Shackell and Doyle, 1991 (in Oreochromis niloticus and El-Fiky, 1993b (in Cyprinus carpio) noticed an accumulation of dermal cells " The scleroblasts" under the epidermis; these cells are considered to be the progenitor cells of the scale anlage.

The fine struciure of the developing scale in cichlid, Henichromis bimaculatus has been described in detail by Sire and Geraudie (1983). They reported that the scale exhibits two distinct layers: 1 , a superficial mineralized osseous layer with its numerous circuli on the anterior and lateral fields and tubercules on the posterior field. 2, a basal fibrillary plate which is made of several lamellae of collagen fibrils organized as in the sheepshead Minnow (Qlson and Watabe, 1980). El-Fiky (1993b), noticed a rapid scale formation on common carp. The osseous layer is the first one to be secreted, presumably by only the scleroblasts. Then the scleroblasts specialized in their functions. Superficial ones are involved in the formation of osseous circuli, marginal scleroblasts are responsible for growth of the scale in diameter while the deep scleroblasts allow the scale to thicken owing to the progressive addition of collagen fibrils which constitute the fibrillary plate of the scale. Minerilzation occurs very rapidly within the osseous layer in the form of crystal deposits. This general principle of teleost scale development seems to be the same in the big head carp. The appearance of the scale was correlated to both the disappearnce of free neuromasts and the full development of the eye. So, we could say that in the developing fish the sequence of the development of the structures necessary for vital functions appears to be well adapted to the demands. 


\section{REFERENCES}

Ali, M. A. (1959). The ocular structure, retinomotor and photobehavioural responses of juvenile Pacific salmon. Can J. Zool., 37:965-996. and D. J. Randell, Fish Physiology, Vol. XI A, 59-162.

Balon, E. K. ; (1985). Early histories of fishes. New developmental, eçological and evolutionary perspectives. Junk, Dordrecht, Boston, Lancaster, 280pp.

Batty, R. S. (1984). Development of swimming movements and musculature of larval herring (Clupea harengusu). J. Exp. Biol., 110:217-229.

Blaxter, J. H. S (1987). Structure and development of the lateral line. Biol. Rev., 62:471-514.

Blaxter, J. H. S and Fuiman, L. A. (1989). Function of the free neuromasts of marine teleost larvae. In " The Mechanosensory lateral line: Neurobiology and Evolution" Ed by Coombs, P., Gorner, H., Munz, Springer-Verlag. New York, pp. 481-499.

Blaxter, J. H. S. (1986). Development of sense organs and behaviour of teleost larvae with special reference to feeding and predator avoidance. Trans. Am. Fish. Soc., 115:98-114.

Blaxter, J. H: S. (1988). Pattern and variety in development in :Hoar and Randall, Fish Physiology, vol. XI A, 1-58.

Blaxter, J. H. S. and Staines, M. (1970). Pure-cone retinae and retinomotor responses in larval teleosts. J. Mar. Biol. Ass. U.K., 50:449-460.

Blaxter, J. H. S. ; Danielssen, D. ; Moksness, E. and Volestand, A. (1983a). Description of the early development of halibut, Hippoglossus hippoglossus and attempts to rear the larvae past first feeding. Marine Biology, 73:99-107. 
Blaxter, J. H. S. ; Gray, A. B. and Best, A. C. G. (1983b). Structure and development of the free neuromasts and lateral line system of the herring. J. Biol. Ass. U. K., 63:247-260.

Branchek, T. and Bremiller, R. (1984). The development of Photoreceptors in the Zebrafish, Brachydanio rerio, II. Function. J. of Comp. Neurology, 224:116-122.

Coughlan, D. J. and Gloss, S. P. (1984). Early morphological development of gills in smallmouth bass (Micropterus dolomieui). Can. J. Zool., 62:951-958.

de Silva C. D. (1974). Development of the respiratory system in herring and plaice larvae. In: Blaxter J. H. S. (ed) The early life history of fish. Springer, Heidelberg, pp. 465-485.

Dijkgraaf, S. (1962). The functioning and significance of the lateralline organs. Biol. Rev., 38:51-105.

Dingerkus, G. and Uhler, L.D. (1977). Enzyme clearing of alcian blue stained whole small vertebrates for demonstration of cartilage. Stain Technol., 52(4): 229-232.

Drost, M. R. ; Muller, M. and Osse, J. W. M. (1988). A quantitative hydrodynamical model of suction feeding in larval fishes the role frictional forces. Proc. R. Roc. London, B234: 263-281.

Díllemeijer, P. (1974). Concepts and approaches in animal Morphology. Van Gorcum. Assen, 264pp.

El-Fiky, N. (1989). Comparative studies on the development of body musculature and gills in the larvae of three species of cyprinids. PH.D. Thesis, Innsbruck university, Austria.

El-Fiky, N. (1994). On the development of the mechanoreceptor, gustatory organs and lateral canals in Tilapia zilli. Bull. Fac. Sci., Zagazig Univ., 16(2): 554-569.

El-Fiky, N. and Wieser, W. (1988). Life styles and patterns of development of gills and muscles in larvae cyprinids (Cyprinidae, Teleostei). J. Fish. Biol., 33: 135-145. 
EL-Fiky, N. Hinterleitner, S. and Wieser, W. (1987). Differentiation of swimming muscles and gills, and development of anaerobic power in the larvae of cyprinid fish (Pisces, Teleostei), Zoomorphology., 107: 126-132.

EL-Fiky, N. ; Attia, $Z$ and Ahmed, A. (2000). Life style and patterns of development of gills and muscles in larvae of Cyprinus carpio, Tilapia zilli and Gambusia affinis. J. Egypt. Ger. Soc. Zool., Vol. 33(B), Anatomy \& Embryology, 103-122.

EL-Fiky, N.. (1993a). Development of some sense organs of Cyprinus carpio and their relation to behaviour. J. Egypt. Ger. Soc. Zool., Vol. 10(b), Anatomy\& Embryology, 273292.

El-Fiky, N. (1993b). Development of the scales in Cyprinus carpio. $J$. Egypt. Ger. Soc. Zool., 10(B), Anatomy and Embryology, 137-149.

Fisher, J. P. and Pearcy, W. G. (1990). Spacing of scale circulversus growth rate in young Coho salmon. Fish. Bull., 88(5): 637644.

Flock, A. (1971). Sensory transduction in hair cells. In Handbook of sensory physiology, Ol. 1, Principles of the Receptor physiology (ed. W.R. Loewenstein), pp. 391-441.

Franklin, D. R. ; Smith, L. L. ; J. R. (1960). Note on development of scale patterns in the Northern pike, Esox lucius L. Trans. Am. Fish. Soc., 98:83-96.

Gumas's, S. A. (1982). Retinal development and retinomotor responses in perch, Perca flwviatilis, J. Fish. Biol., 20:611618.

Harvey, R. Blaxter, J. H. S. and Hoyt, R. D. (1992). Development of superficial and lateral line neuromasts in larvae and juveniles of place (Pleuronectes platessa) and sole (Solea solea). J. Mar. Biol. Ass U.K., 72:651-668. 
Hinterleitner, S. ; Wieser, W. and EL-Fiky, N. (1989). Profiles of enzymes actively in larvae of two cyprinid species with contrasting life styles (cyprinidae, Teleostei). J. Fish. Physiology., 14:34-48.

Hoda, S. M. S. and Tsukahara, H. (1971). Studies on the development and relative growth on the carp (Cyprinus carpio). J.Fac. Agriculture Kyushu Uni., 16(4):387-509.

Houde, E. D. (1987). Fish early life dynamics and recruitment variability. Am. Fish. Soc. Symp., 2:17-29.

Hughes, G. M. (1984). General anatomy of the gills. In: Hoar W.S. and Randall D.J. (eds) Fish Physiology Vol 10, Part A, Academic Press, New York, pp. 1-22.

Hunter, J. R. (1972). Swimming and feeding behaviour of larval anchovy, Engraulis mordax. Fish. Bull., 70:821-838.

Iwai, T. (1965). Notes on the cupulae of free neuromasts in larvae of the goldfish. Copeia., 1965:379.

Iwai, T. (1967). Structure and development of lateral line cupulae in teleost larvae. In"Lateral Line Detectors" Ed by P, Cahn, Indiana Univ Press, Bloomington, pp. 27-44.

Iwai, T. (1972). On the free neuromasts of some teleost larvae. Japan J. Ichthyol, 19:307-311 (In Japanese with English abstract ).

Johns, P. R. (1981). Growth of fish retinas. Amer. Soc, Zool., 21:447$4 \dot{58}$.

Jolliee, M. (1983). Development of the head skeleton and pectoral girdle of salmons, with a note on the scales. Can. J. Zool., 52:1757-1778.

Jones, W. R. and Janssen, J. (1992). Lateral line development and feeding behaviour in the mottled sculpin, Cottus bairdi (Scor-paeniformes:Cottidae). Copeia, 92:485-492. 
Kawamura, G. and Ishida, K. (1985). Changes in sense organ morphology and behaviour with growih in the flounder, Paralichthys olivaceus, Bull. Japan. Soc. Sci. Fish., 49:1527-1532.

Kawamura, G. Washiyama, N. (1989). Ontogenetic changes in behaviour and sense organ morphogenesis in largemouth bass and Tilapia nilotica. Trans. Am. Fish. Soc., I18:203213.

Kawamura, G., Tsuda, R. and Kumai, H. (1984). The visual cell morphology of Pagrus major and its adaptive changes with shift from pelagic to benthic habitats. Bull. Japan. Soc. Sci. Fish., 50(12): 1975-1980.

Kawase, H. (1996). Radial polarity of the first neuromast in $\therefore$ embryonic American shad, Alosa sapidissima (Teleostei:Clupeomorpha). Copeia, 1: 226-228.

Kendall, A. W. ; jr. ; Ahlstrom, E. M. and Moser, H. G. (1984). Early life history stages of fishes and their characters. In: Ontogeny and systematics of fishes. Moser, H.G. et al, (Ed) Spec. Publ. I, Am. Soc. For Ichthyologists and Herpetologists. Allen Press, Lawrence, Kansas, 760pp.

Kunz, Y. W. ; Ennis, S. and Wise, C. (1983). Ontogeny of the photoreceptors in embryonic retina of the viviparous teleost, Poceilla reticulate (Teleostei). Cell and Tissue research., 230:469-486.

Lanzig, W. J. R. and Wright, R.G. (1976). The ultrastructure and calcification of the scales of Tilapia mossambica (Perters). Cell Tissue Res., 167:37-47.

Maekawa, K. and Yamada, J. (1972). Morphological identification of cells involved in the growth of the goldfish scale. Jap. J. Ichthyol., 19:1-10. 
Mark, W. ; Wieser, W. ; Hohenauer, C. (1989). Interactions between developmental processes, growth and food selection in the larvae and Juveniles of Rutilus rutilus (L).. Cyprinidae. Oecologia, 78: 330-337.

Morgan, M. (1974). Development of secondary lamellae of the gills of the trout, Salmo gairdneri (Richardson). Cell Tissue Res., 151:509-523.

Mukai, Y. ; Kobayashi, H. and Yoshikawa, H. (1992). Development of free and canal neuromasts and their directions of maximum sensitivity in the larvae of Ayu, Plecoglossus altivelis. Jap. Ichthyology., 38:332-341.

Mukai, Y. and Kobayashi, H. (1992). Cupular growth rate of free neuromasts in three species of cyprinid fish. Nippon Suisan Gakkaishi, 58:1849-1853.

Mukai, Y. and Kobayashi, H. (1994). Development of free neuromasts in larvae of cyprinid fish. Mem. Fac. Agr. Kinki Univ., 27:1-14.

Munz, F. W. (1971). Vision: visual pigments. In W.S. Hoar, and D.J. Randall (eds), Fish physiology, vol. 5, Sensory systems and electric organs, pp. 1-8. Academic Press, New York, NK.

Nag and Nursall, J.R. (1972). Histogenesis of white and red fibers of the trunk muscle of a fish, Salmo gaitdneri. Cytobios, 6:226247.

Neave, D. A. (1984). The development of visual acuity in larval plaice (Pleuronectes platessa L.) and turbot (Scophthalmus maximus L.) J. Exp. Mar. Biol. Ecol., 78:167-175.

O'Connell, C. P. (1980). Percentage of starving northern anchovy, Engraulis mordax, larvae in

O'connell, C. P. (1981). Development of organ systems in the Northern anchovy, Engraulis mordax and other teleosts. Amer. Zool., 21:429-446. 
Oikawa, S. and Itazawa, Y. (1985). Gills and body surface areas of carp in relation to body mass, with special reference to metabolism-size relationship. J.Exp. Biol., 117: 1-14.

Olson, O. P. ; and Watabe, N. (1980). Studies on the formation and resorption of fish scales. IV-Ultrastructure of developing scales in newly hatched fry of the sheepshead Minnow. Cyprinodon variegates (Atheriniformes): Cyprinodontidae). Cell Tissue Res., 211:303-316.

Park, E. H. and Kim, S. D. (1984). A procedure for staining cartilage and bone of whole vertebrate larvae while rendering all other tissues transparent. Stain Technol., 59(5):24-37.

Porter, S. M. and Theilacker, G. H. (1999). The development of the digestive tract and eye in larval Walleye Pollock, Theragra chalcogramma. Fishery Bulletin., 97(3): 77-83.

Proctor, C. ; Mosse, P. R. L. and Hudson, R. C. L. (1980). A histochemical and ultrastructural study of the development of the propulsive musculature of the brown trout, Salmo trutta L., in relation to its swimming behaviour. J.Fish. Biol., 16:309-329.

Rombough, P. J. (1988). Respiratory gas exchange, aerobic metabolism and effects of hypoxia during early life. In Hoar W.S. and D.J. Randell, Fish Physiology, Vol. XI A, pp. 59162.

Sandy, M. J. and Błaxter, J. H. S. (1980). A study of retinal development in larval herring and sole. J.Mar.Biol. Ass. U.K., 60:59-71.

Shackell, N. L. and Doyle, R.W. (1991). Scale morphology as an index of developmental stability and stress resistance of Tilapia (Oreochromis niloticus). Can. J. Fisheries Aquat. Sci., 48(9):1662-1669.

Sire, J. Y: and Geraudie, J. (1983). Fine structure of the developing scale in the cichlid Hemichromis bimaculatus (Pisces, Teleostei, Perciformes). Acta Zoological (Stockh.), 64:1-8. 
ONTOGENETIC CHANGES IN SOME STRUCTURES 249 OF ARISTICHTHYS NOBILIS

Talesara, C. L. ; Urfi, A. J. (1987). A histophysiological study of muscle differentiation and growth in the common carp, $\mathrm{Var}$. communis. J. Fish Biol., 31:45-54.

Timmermans, L. P. M. (1987). Early development and differentiation in fish. Sarsia, 72: 331-339.

Van Ramsdonk, W. ; Pool, C. W. and te Kronnie, G. (1978). Differentiation of muscle fiber types in the teleost Brachydanio rerio. Anat. Embryol., 153:137-155.

Van Raamsdonk, W. ; van't Veer, L. ; Veeken, K. ; teKronnie, T. and de Jager, S. (1982). Fiber type differentiation in fish. Molec. Physiol., 2:31-47.

Wapp, P. W. (1975). Hydrodynamics and energetics of sish propulsion. Fisheries Research Board of Canada Bulletin, 190.

Waterman, R. E. (1970). Fine structure of scale development in the teleost, Brachydanio rerio. Anat. Rec., 168:361-380.

Yamada, J. (1971). A fin structural aspect of the development of sçales in the chum salmon fry. Bull. Jap. Soc. Scient. Fish., $37: 18-29$. 


\section{LEGEND OF FIGURES}

Pl. (1). (a) Whole mount preparation and (b) longitudinal section through the pharyngeal region of newly harched larvae showing presence of four gill arches (I - IV). (c), whole mount of gill filament ( $\mathrm{f}$ ) of larva 3 days after hatching showing small protuberances or presumptive secondary lamellae (sl) on both sides of filament. (d), whole mount of larva of 4-day-old larva which possess four gill arches with series of relatively short filaments, each bearing secondary lamellae on both sides. (e), whole mount of pharyngeal region of 7-day-old larva showing progressively more secondary lamellae (sl) appear. Alcian and alizarin red stain for whole mount and Haematoxylin \& eosin stain, for sections. X 200 (for a,d and e), X 250 (for b) and X 400 (for c).

P1. (2). (a), Transverse section throught the body of pre-hatched embryo, showing scattered undifferentiated myoblasts (mb). (b), cross section through the trunk region of post hatching larva, showing respiratory red layer (rl) which is completely separated from underling white muscle mass (wm). (c), transverse section through the body of 7-day-old larva,showing the small red muscle mass ( $\mathrm{rm}$ ) splitting from the red layer. Haematoxylin \& eosin stain. X 350

Pl. (3). (a), Scanning electron micrograph of post-hatching larva, showing the distribution of free neuromasts (arrows). The newly hatched larva has few number of free neuromastss on the head region . (b and c) larvae after 26 hours for hatching showing about 12 neuromasts on each side arranged between the eyes (e) and around the nasal cavities (n). (d), 2-day-old larva showing about 20 prominent neuromasts on each side of the body. (e), In 6-day-old larva, the cupulae are arranged in a line on the trunk and protruded from the body surface. Scale bars indicate $100 \mathrm{um}$.

Pl. (4). (a- f)), Transverse sections throught the eye region. (a), the eye of newly hatched larva which is not pigmented and the lens (l) and retina (r) are poorly differentiated. (b), 8 hours after hatching, showing eye lens (l),ganglionic layer, $(\mathrm{g})$, and inner nuclear layer, (in). (c), 20-hour-old larva showing stratifications of retina began, an inner ganglionic layer ( $g$ ), pale pigment epithelial layer (pe), outer segment of single cone (os), inner plexiform (ip) inner nuclear layer (in) and eye 
lens (l). (d), at 3 day larva, the the outer and inner plexiform layers are formed. ( $e$ and $f$ ), at 4 day larva, the pigment epiţhelial layer (pgl) becomes thicker, the cones are formed (cone ellipsoid, ce and cone nuclei, $c n$ ). X 180 for ( $a$ and b), X 220 for $c, d$ and e) X 250 (for f).

PI. (5). (a), Vertical section through the skin of 6-day-old -larva, showing an outer layer of epidermis and defferntiating scleroblasts (s). (b-e), whole mount of isolated scales. (b), 8 day- old larva showing the second circulus (arrow) which is set parallel and outside the first one. Note complete minerization towards the posterior field (pf). (c and d), whole mount of isolated scale from 10-day-old larvae showing the addition of new circuli. Minerization only clear on the posterior field (pi) and absent on the anterior field (ai). (e), isolated scale from 14-day-old larva showing 8 radii ( $r$ ). $X$ 250 (for a) and X 50 (for b-e). 


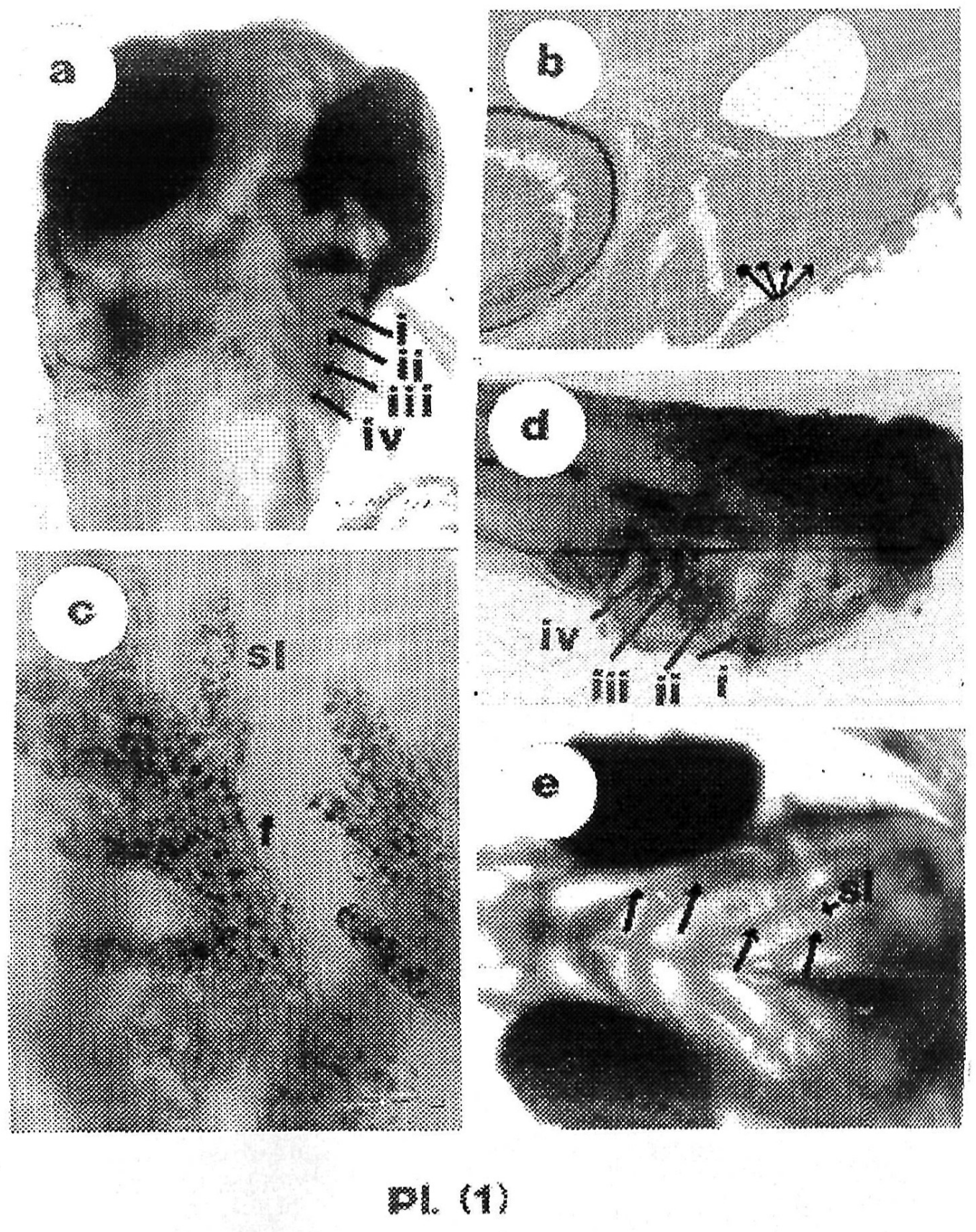



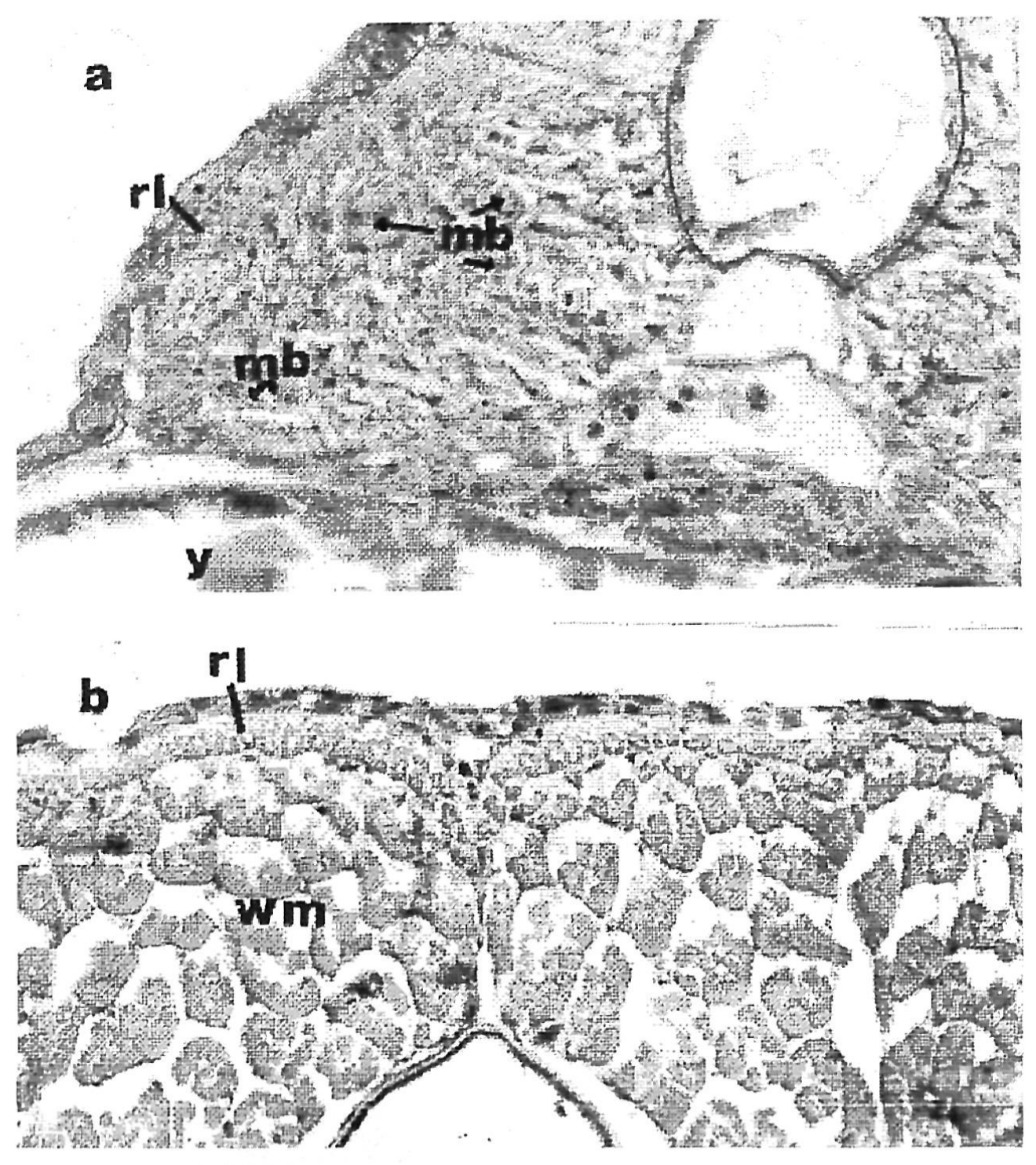

\section{$c$}

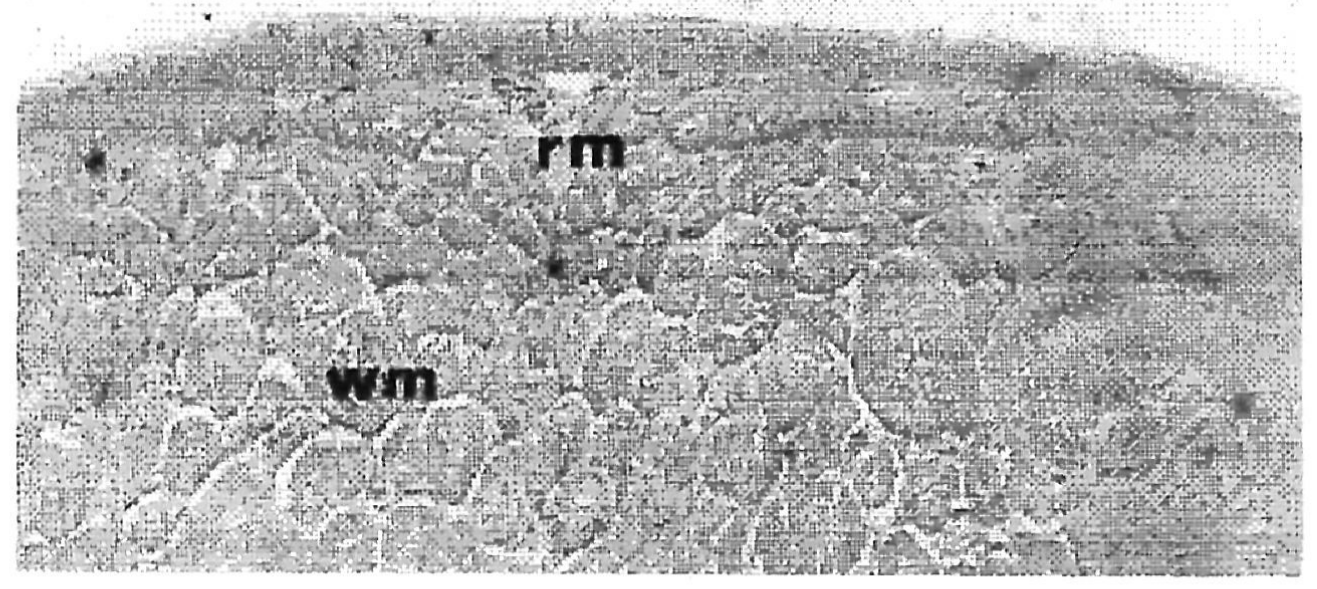



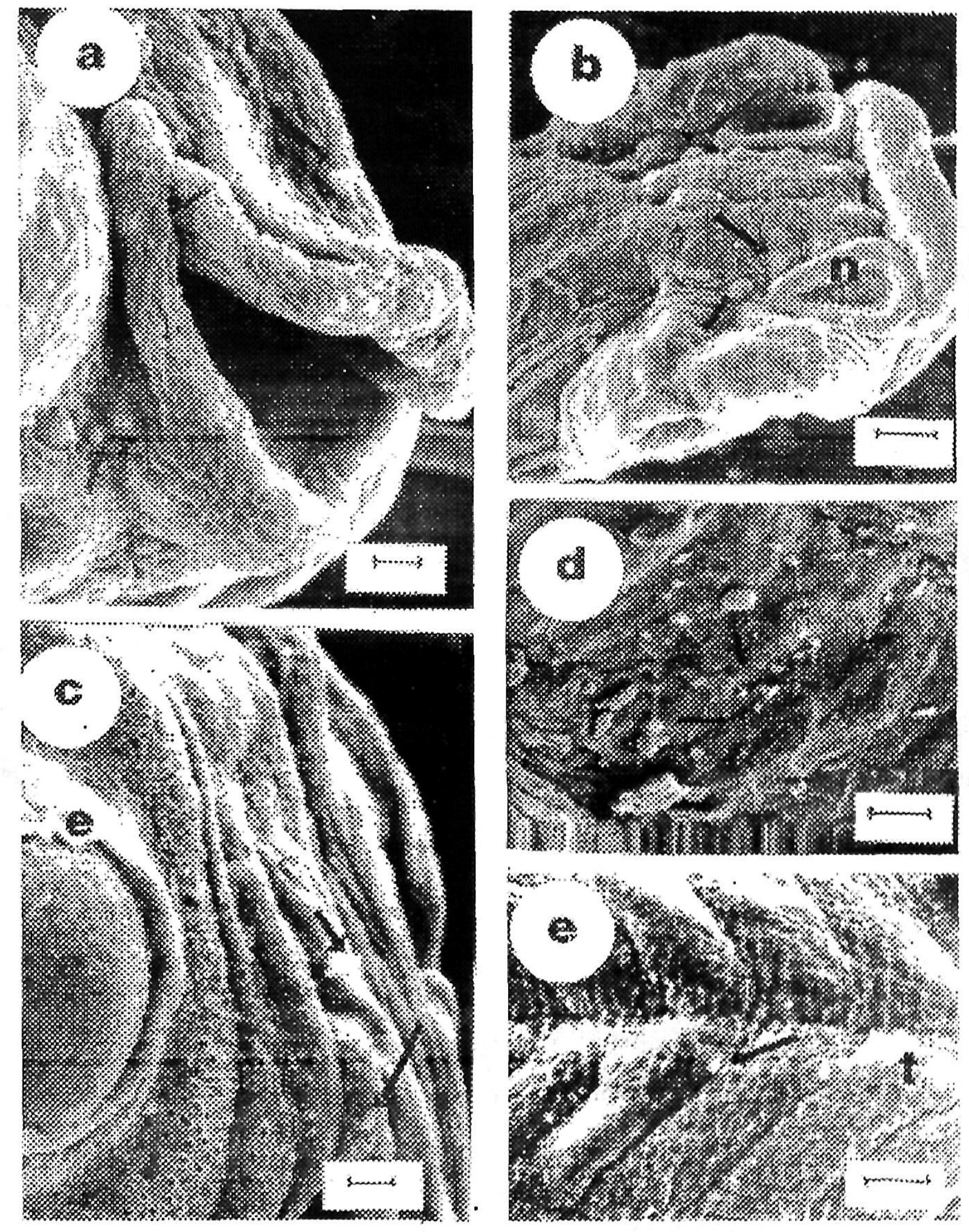

PI. (3) 

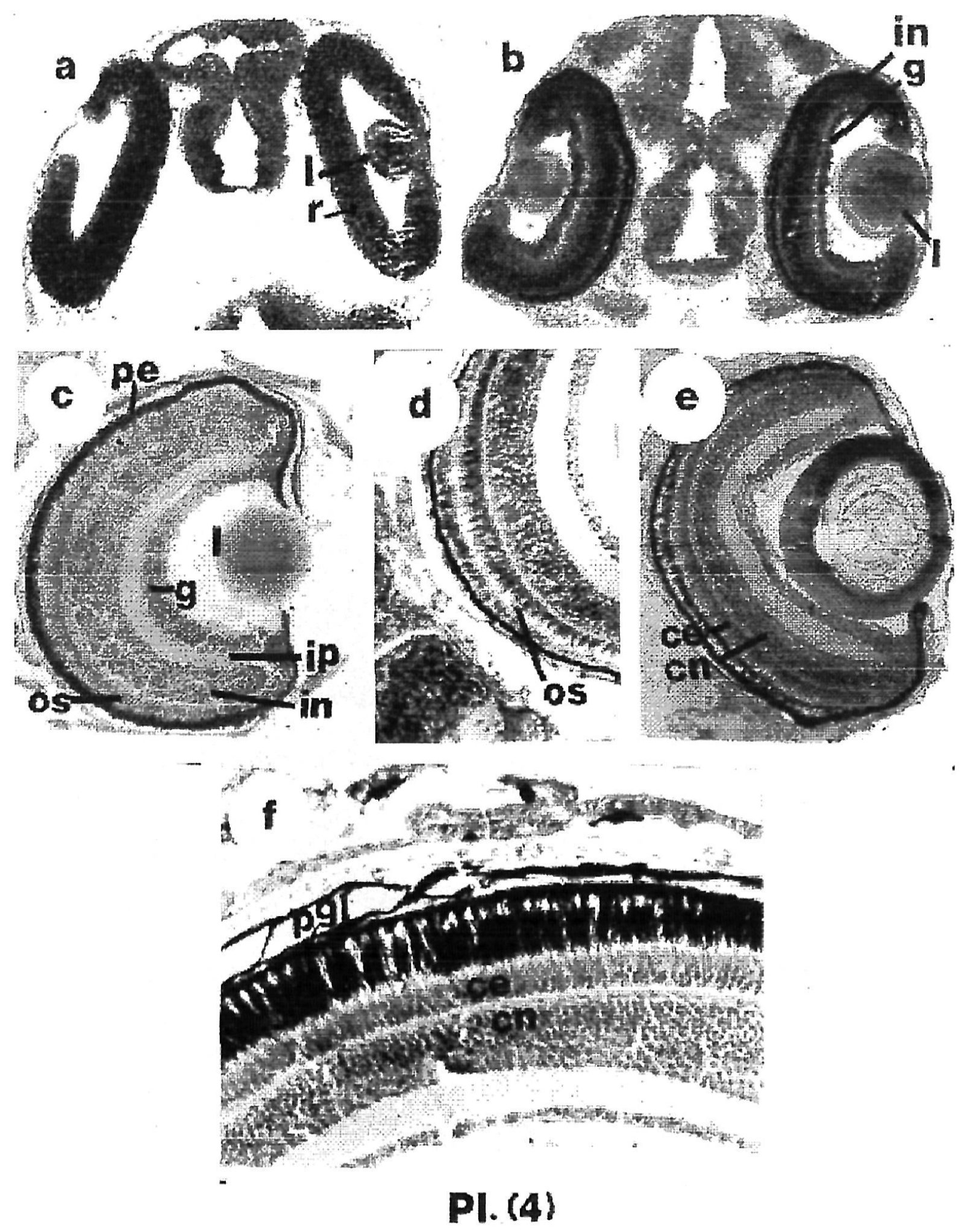

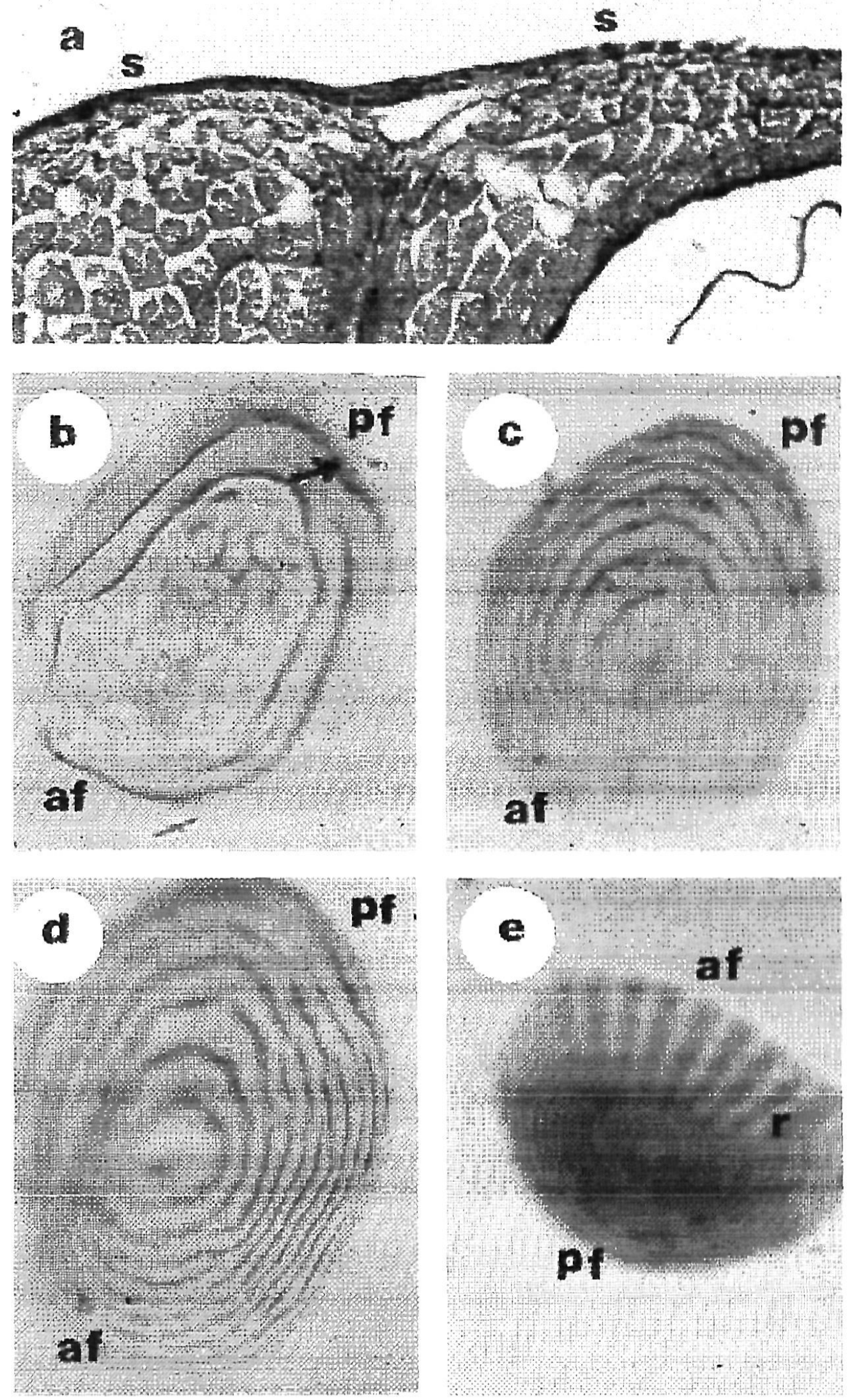

PI. (5) 